\title{
Associated factors with poor treatment response to initial glucocorticoid therapy in patients with adult- onset Still's disease
}

\section{Fumiaki Kondo}

Tokyo Medical and Dental University Graduate School of Medical and Dental Sciences: Tokyo Ika Shika Daigaku Daigakin Ishigaku Sogo Kenkyuka

Takahiko Sugihara ( $\nabla$ takahikosugihara03240925@gmail.com )

Tokyo Medical and Dental University Graduate School of Medical and Dental Sciences: Tokyo Ika Shika Daigaku Daigakin Ishigaku Sogo Kenkyuka https://orcid.org/0000-0002-7181-7494

\section{Natsuka Umezawa}

Tokyo Medical and Dental University Graduate School of Medical and Dental Sciences: Tokyo Ika Shika Daigaku Daigakin Ishigaku Sogo Kenkyuka

\section{Hisanori Hasegawa}

Tokyo Medical and Dental University Graduate School of Medical and Dental Sciences: Tokyo Ika Shika Daigaku Daigakin Ishigaku Sogo Kenkyuka

\section{Tadashi Hosoya}

Tokyo Medical and Dental University Graduate School of Medical and Dental Sciences: Tokyo lka Shika Daigaku Daigakin Ishigaku Sogo Kenkyuka

\section{Naoki Kimura}

Tokyo Medical and Dental University Graduate School of Medical and Dental Sciences: Tokyo Ika Shika Daigaku Daigakin Ishigaku Sogo Kenkyuka

\section{Masaaki Mori}

Tokyo Medical and Dental University Graduate School of Medical and Dental Sciences: Tokyo Ika Shika Daigaku Daigakin Ishigaku Sogo Kenkyuka

\section{Shinsuke Yasuda}

Tokyo Medical and Dental University Graduate School of Medical and Dental Sciences: Tokyo lka Shika Daigaku Daigakin Ishigaku Sogo Kenkyuka

\section{Research article}

Keywords: Adult-onset Still's disease, poor prognostic factor, white blood cell

Posted Date: October 26th, 2021

DOI: https://doi.org/10.21203/rs.3.rs-1001506/v1 
License: (c) (i) This work is licensed under a Creative Commons Attribution 4.0 International License. Read Full License 


\section{Abstract \\ Background}

High-dose glucocorticoids (GC) are first-line treatment for adult onset Still's disease (AOSD), however some of the patients remain refractory to initial GC therapy, or rapidly relapse. The aim of this study was to identify prognostic factors for poor treatment response to initial GC therapy for AOSD.

\section{Methods}

Data on newly-diagnosed AOSD patients were extracted from our database ( $n=71$, mean age 51.6 years). The primary outcome was a poor treatment outcome at 4 weeks, which was defined as failure to achieve remission or relapse after achieving remission within 4 weeks, followed by administration of two or more rounds of GC pulse therapy or of any other immunosuppressive drugs.

\section{Results}

The initial mean dose \pm standard deviation of prednisolone was $0.82 \pm 0.23 \mathrm{mg} / \mathrm{kg} / \mathrm{day}$, and 34 (47.3\%) patients received GC pulse therapy at week 0 . Twenty-nine of 71 patients exhibited a poor treatment outcome at 4 weeks (40.8\%). The second round of GC pulse therapy or immunosuppressive drugs was added in 17 or 24 of the 29 patients, respectively. These patients had higher baseline white blood cell (WBC) counts, serum ferritin levels, systemic feature score based on clinical symptoms (modified systemic feature score, mSFS), more hemophagocytic syndrome (HPS) over the 4 weeks, and the higher severity score based on modified Pouchot score or severity index of the Japanese Ministry of Health, Labour and Welfare, than the remaining 42 patients. Multivariable logistic regression model identified baseline WBC count as a prognostic factor for poor outcome (odds ratio per 1,000/ $\mu \mathrm{l}$ increment: 1.12, 95\% Cl 1.04-1.29), while thrombocytopenia, hyperferritinemia, and mSFS at baseline did not achieve statistical significance. Receiver-Operating Characteristic curve analysis showed that the optimal cut-off for WBC count was $13,050 / \mu \mathrm{l}$. The Kaplan-Meier method showed the cumulative rate of poor treatment outcome to be $60.0 \%$ in patients with WBC $\geq 13,050 / \mu$ land $23.5 \%$ in those with WBC $<13,050 / \mu$ l.

\section{Conclusions}

A higher WBC count but not thrombocytopenia, hyperferritinemia, and mSFS at baseline was a significant prognostic factor for poor treatment outcome at week 4 in this retrospective cohort of AOSD patients. Our findings provide important information for determining the initial treatment strategy of newly-diagnosed AOSD.

\section{Background}


Adult onset Still's disease (AOSD) is a systemic inflammatory disease first reported by Bywaters in 1971 (1). Clinical signs and symptoms of AOSD include fever, arthritis, typical skin rash, myalgia, lymphadenopathy and serositis, and hemophagocytic syndrome (HPS) (2). While high-dose glucocorticoids (GC) are first-line treatment for AOSD (3), GC pulse therapy is frequently added to oral GC in the induction treatment regimen (4). However, some patients remain refractory to the induction therapy, or rapidly relapse; hence there is an unmet need to understand treatment failures and develop alternative strategies.

A recent randomized controlled trial has documented the efficacy of the anti-IL- 6 receptor antibody tocilizumab for AOSD refractory to GC therapy (5). As we embark on a new era of AOSD treatment and develop novel treatment strategies, prognostic factors for initial treatment response to standard doses of oral GC with or without GC pulse therapy are important for determining indications for additional treatments including other immunosuppressive drugs or tocilizumab.

Severe macrophage activation syndrome (MAS) often accompanies a fatal course of systemic juvenile idiopathic arthritis (sJIA), associated with multiple organ damage, disseminated intravascular coagulation (DIC), and HPS (6). Because the clinical features of AOSD are similar to SJIA (7), and severe MAS in both SJIA or AOSD is treated with repeated GC pulse therapy together with high-dose oral GC, immunosuppressive drugs, TNF inhibitors, or tocilizumab (8-10), the experience with sJIA suggests that high serum ferritin and cytopenia due to MAS might be associated with poor treatment response to initial GC therapy also in AOSD. Thus, we hypothesized that white blood cell (WBC) counts, platelet (PIt) counts, aspartate aminotransferase (AST), lactate dehydrogenase (LDH), ferritin, and clinical signs and symptoms of organ damage due to AOSD determine the patient's response to initial high-dose GC. Here, we have investigated whether these candidate factors are associated with poor treatment outcomes in patients with AOSD using one-year follow-up data from our retrospective cohort study.

\section{Methods}

\section{Database.}

Patients aged $\geq 16$ years with a diagnosis of AOSD were selected consecutively from 2007 to 2019 from the inpatient database of Tokyo Medical and Dental University. The inpatient database was created for all hospitalized patients, and data on all of those with AOSD were extracted without any exclusions. Patient data were extracted using a pre-defined case report form at one week and 2, 3, 4, 8, and 52 weeks after the start of GC treatment. The diagnosis of AOSD was made at the discretion of the attending physician based on Yamaguchi's classification criteria (11). Clinical signs and symptoms of AOSD, WBC, PIt, AST, $\mathrm{LDH}$, and serum ferritin at each time point were extracted from the medical records.

\section{Outcomes.}

The primary outcome was a poor treatment outcome at 4 weeks, i.e., having a poor treatment response event defined as administration of two or more rounds of GC pulse therapy or of any other 
immunosuppressive drugs within 4 weeks due to failure to achieve remission or due to relapse after achieving remission. Remission was indicated by the resolution of clinical signs and symptoms related to AOSD activity (defined as having fever $\left(>39.0^{\circ} \mathrm{C}\right.$ ), weight loss or fatigue, myalgia, arthritis, rashes, lymphadenopathy, sore throat, hepatosplenomegaly, abnormal liver function tests, pericarditis, pleuritis, interstitial lung disease, HPS, DIC and/or elevation of C-reactive protein (CRP) levels). The presence of HPS was determined based on definitive diagnosis by bone marrow aspiration or biopsy. The diagnosis of DIC was made based on the diagnostic criteria of the Japanese Society on Thrombosis and Hemostasis (12). Relapse was determined as having occurred if disease activity reappeared after achievement of clinical remission, and required increased GC doses or the addition of immunosuppressive drugs.

\section{Definition of the modified systemic feature score, modified Pouchot score, and severity index.}

The severity of organ damage due to AOSD was evaluated using items describing clinical signs and symptoms in the original systemic feature score (13) (modified systemic feature score, mSFS). This included fever, rash, lymphadenopathy, hepatosplenomegaly, and serositis. Each clinical feature was assigned a score of 1 (present) or 0 (absent).

Modified Pouchot scores (14) and the severity index of the Japanese Ministry of Health, Labour and Welfare (Severity Index) (15) were also evaluated. The modified Pouchot score included fever, evanescent rashes, sore throat, arthritis, myalgia, pleuritis, pericarditis, pneumonitis, lymphadenopathy, hepatomegaly or abnormal liver function tests, elevated leukocyte counts $(>15,000 / \mu \mathrm{l})$, and serum ferritin $(>3,000 \mu \mathrm{g} / \mathrm{l})$. Each clinical or laboratory feature was also assigned a score of 1 (present) or 0 (absent). The Severity Index was calculated as the sum of the following scores: serositis (1), neutrophil ratio $>85 \%$ (1), serum ferritin $>3000 \mathrm{ng} / \mathrm{ml}$ (1), prominent lymphadenopathy (1), refractoriness to GC therapy $(>0.4 \mathrm{mg} / \mathrm{kg}$ of prednisolone equivalent) (1), HPS (2), and DIC (2).

\section{Safety.}

Serious adverse events of interest were assessed by collecting information for 0-52 weeks after the start of treatment. The development of serious infections including bacterial pneumonia, other bacterial infections, pneumocystis pneumonia, deep fungal infections, herpes zoster, tuberculosis, non-tuberculous mycobacterial infections and cytomegalovirus infection, fractures, and death were evaluated.

\section{Statistics.}

Student's t test and the Mann-Whitney test were used to compare continuous variables depending on their distribution, and the chi-square test and Fisher's exact test were used for categorial variables.

Univariable analysis and multivariable analysis for factors associated with poor treatment outcomes at 4 weeks were conducted using logistic regression analysis. Receiver-operating characteristic (ROC) curves were constructed to evaluate the predictivity of identifying patients with poor treatment outcomes. Cumulative rates and median time to the first event of the poor treatment outcomes within 28 days were 
analyzed using the Kaplan-Meier method and log-rank testing. All statistical analyses were performed using IBM Statistical Package for the Social Sciences version 24 (IBM, Armonk, NY, USA). All reported $p$ values are two-tailed, and the level of significance is taken as $p<0.05$.

\section{Results}

\section{Patient characteristics.}

The case report forms of 71 newly-diagnosed Japanese AOSD patients were assessed, confirming that all of them satisfied Yamaguchi's classification criteria after exclusion of those with infectious, neoplastic, and other autoimmune disorders. The mean age \pm standard deviation (S.D.) was $51.6 \pm 18.1,50$ were women $(70.4 \%), 42(59.2 \%)$ had high fever $\left(>39^{\circ} \mathrm{C}\right)$ at baseline, $55(77.5 \%)$ had a typical rash, $50(70.4 \%)$ had a sore throat, $47(66.2 \%)$ had arthritis, and 27 (14.1\%) had HPS (Table 1). 
Table 1

Clinical characteristics of patients at onset

\begin{tabular}{|c|c|c|c|c|}
\hline & $\begin{array}{l}\text { All } \\
(n=71)\end{array}$ & $\begin{array}{l}\text { With the } \\
\text { event }^{a} \\
(n=29)\end{array}$ & $\begin{array}{l}\text { Without the } \\
\text { event } \\
(n=42)\end{array}$ & $\begin{array}{l}p- \\
\text { value }\end{array}$ \\
\hline Age, years, mean $\pm S D$ & $51.6 \pm 18.1$ & $54.5 \pm 18.9$ & $49.6 \pm 17.5$ & 0.262 \\
\hline Female patients, $\%$ & 70.4 & 69.0 & 71.4 & 0.823 \\
\hline Weight, kg, mean \pm SD & $56.6 \pm 12.1$ & $56.5 \pm 9.55$ & $56.6 \pm 13.8$ & 0.967 \\
\hline Fever $\left(>39.0^{\circ} \mathrm{C}\right), \%$ & 59.2 & 72.4 & 50.0 & 0.059 \\
\hline Weight loss or fatigue, $\%$ & 62.0 & 55.2 & 66.7 & 0.327 \\
\hline Myalgia, \% & 32.4 & 37.9 & 28.6 & 0.407 \\
\hline Rashes, \% & 77.5 & 79.3 & 76.2 & 0.757 \\
\hline Lymphadenopathy, \% & 71.8 & 75.9 & 69.0 & 0.530 \\
\hline Sore throat, \% & 70.4 & 75.9 & 66.7 & 0.404 \\
\hline Hepatosplenomegaly, \% & 60.6 & 69.0 & 54.8 & 0.229 \\
\hline Pericarditis, \% & 7.0 & 13.8 & 2.4 & 0.086 \\
\hline Serositis, \% & 12.7 & 27.6 & 2.4 & 0.003 \\
\hline Interstitial lung disease, \% & 7.0 & 10.3 & 4.8 & 0.327 \\
\hline Arthritis \% & 66.2 & 72.4 & 63.4 & 0.430 \\
\hline Hemophagocytic syndrome, \% & 14.1 & 24.1 & 7.1 & 0.048 \\
\hline DIC, \% & 5.6 & 6.9 & 4.8 & 0.542 \\
\hline mSFS score, mean \pm SD & $3.25 \pm 0.91$ & $3.59 \pm 0.91$ & $3.02 \pm 0.84$ & 0.009 \\
\hline $\mathrm{WBC}, / \mu \mathrm{l}$, mean $\pm \mathrm{SD}$ & $\begin{array}{l}13919 \pm \\
7018\end{array}$ & $17097 \pm 7087$ & $\begin{array}{l}11615 \pm \\
6072\end{array}$ & 0.001 \\
\hline
\end{tabular}

a Patients who received two and more pulse glucocorticoid (GC) therapy or any immunosuppressive drugs within 4 weeks due to disease progression or relapse were defined as having the event of the poor treatment outcome at week 4.

WBC, white blood cell; $\mathrm{Hb}$, hemoglobin; Plt, platelet count; ESR, erythrocyte sedimentation rate; CRP, Creactive protein; $\mathrm{LDH}$, lactate dehydrogenase; $A S T$, aspartate transferase; $A L T$, alanine aminotransferase; DIC, disseminated intravascular coagulation; mSFS, modified systemic feature score; Severity index; severity index of Japanese Ministry of Health, Labour and Welfare; PSL, prednisolone. 


\begin{tabular}{|c|c|c|c|c|}
\hline & $\begin{array}{l}\text { All } \\
(n=71)\end{array}$ & $\begin{array}{l}\text { With the } \\
\text { event }^{a} \\
(n=29)\end{array}$ & $\begin{array}{l}\text { Without the } \\
\text { event } \\
(n=42)\end{array}$ & $\begin{array}{l}p- \\
\text { value }\end{array}$ \\
\hline neutrophil, $/ \mu \mathrm{l}$, mean \pm SD & $\begin{array}{l}11871 \pm \\
6734\end{array}$ & $14855 \pm 6832$ & $9651 \pm 5806$ & 0.001 \\
\hline $\mathrm{Hb}, \mathrm{g} / \mathrm{dl}$, mean $\pm \mathrm{SD}$ & $11.1 \pm 1.7$ & $11.2 \pm 1.4$ & $11.1 \pm 1.9$ & 0.866 \\
\hline $\mathrm{Plt}, \times 10^{4} / \mu \mathrm{l}$, mean $\pm \mathrm{SD}$ & $27.2 \pm 13.6$ & $24.6 \pm 11.6$ & $29.1 \pm 14.8$ & 0.178 \\
\hline $\mathrm{ESR}$, mean $\pm \mathrm{SD}$ & $84.5 \pm 35.3$ & $75.1 \pm 35.2$ & $90.2 \pm 34.6$ & 0.652 \\
\hline $\mathrm{CRP}, \mathrm{mg} / \mathrm{dl}$, mean $\pm \mathrm{SD}$ & $12.7 \pm 8.9$ & $14.7 \pm 8.8$ & $11.2 \pm 8.8$ & 0.102 \\
\hline AST, U/I, median (interquartile range) & $\begin{array}{l}53.5 \\
(30.0-85.0)\end{array}$ & $\begin{array}{l}69.0 \\
(51.0-137.0)\end{array}$ & $\begin{array}{l}45.0 \\
(23.0-82.0)\end{array}$ & 0.011 \\
\hline ALT, U/I, median (interquartile range) & $\begin{array}{l}43.3 \\
(20.0-81.0)\end{array}$ & $\begin{array}{l}47.5 \\
(27.0-109.0)\end{array}$ & $\begin{array}{l}34.0 \\
(17.0-70.0)\end{array}$ & 0.081 \\
\hline LDH, U/l, median (interquartile range) & $\begin{array}{l}438 \\
(230-670)\end{array}$ & $\begin{array}{l}612 \\
(390-928)\end{array}$ & $\begin{array}{l}331 \\
(198-547)\end{array}$ & $<0.001$ \\
\hline $\begin{array}{l}\text { Ferritin, ng/ml, median (interquartile } \\
\text { range) }\end{array}$ & $\begin{array}{l}4548 \\
(616- \\
10323)\end{array}$ & $\begin{array}{l}5850 \\
(3459- \\
32902)\end{array}$ & $\begin{array}{l}1337 \\
(428- \\
7898)\end{array}$ & 0.001 \\
\hline $\operatorname{lgG}, \mathrm{mg} / \mathrm{dl}$, mean \pm SD & $1551 \pm 747$ & $1372 \pm 438$ & $1687 \pm 896$ & 0.093 \\
\hline Modified Pouchot score, mean \pm SD & $6.25 \pm 1.8$ & $7.28 \pm 1.62$ & $5.55 \pm 1.57$ & $<0.001$ \\
\hline Severity index, mean \pm SD & $3.32 \pm 1.62$ & $4.14 \pm 1.64$ & $2.76 \pm 1.36$ & $<0.001$ \\
\hline Calendar year & $2012.5 \pm 4.1$ & $2012.8 \pm 4.3$ & $2012.3 \pm 4.1$ & 0.745 \\
\hline \multicolumn{5}{|c|}{$\begin{array}{l}\text { aPatients who received two and more pulse glucocorticoid (GC) therapy or any immunosuppressive } \\
\text { drugs within } 4 \text { weeks due to disease progression or relapse were defined as having the event of the } \\
\text { poor treatment outcome at week } 4 \text {. }\end{array}$} \\
\hline $\begin{array}{l}\text { WBC, white blood cell; Hb, hemoglobin; } \\
\text { reactive protein; LDH, lactate dehydrog } \\
\text { aminotransferase; DIC, disseminated in } \\
\text { score; Severity index; severity index of } \\
\text { prednisolone. }\end{array}$ & $\begin{array}{l}\text { platelet count; } \\
\text { se; AST, asparta } \\
\text { /ascular coagul } \\
\text { anese Ministry }\end{array}$ & $\begin{array}{l}\text { R, erythrocyte } \\
\text { transferase; } A L \\
\text { ion; mSFS, mod } \\
\text { Health, Labour }\end{array}$ & $\begin{array}{l}\text { imentation rate } \\
\text { alanine } \\
\text { ed systemic fea } \\
\text { d Welfare; PSL, }\end{array}$ & $\begin{array}{l}\text { CRP, C- } \\
\text { ure }\end{array}$ \\
\hline
\end{tabular}

\section{Initial treatment response to GC therapy.}


The initial mean dose \pm S.D. of prednisolone was $0.82 \pm 0.23 \mathrm{mg} / \mathrm{kg} / \mathrm{day}$, and $34(47.3 \%)$ patients received GC pulse therapy at week 0 . Clinical signs and symptoms resolved within 4 weeks in $42(59 \%)$ of the patients, but the remaining 29 had a poor treatment outcome at week 4 despite initiation of GC therapy (Figure 1). Fever $\left(>39.0^{\circ} \mathrm{C}\right)$ was reported in $16(55.2 \%)$ of these 29 patients at the event of poor treatment outcome, elevated liver enzymes in 17 (58.6\%), pericarditis in $3(10.3 \%)$, pleuritis in $5(17.2 \%)$, arthritis in 11 (37.9\%) and HPS in 4 (13.8\%) (Table 2). A second round of GC pulse therapy at the event of poor treatment outcome was added in $17(58.6 \%)$ of the 29 poorly-responding patients, and immunosuppressive drugs were added in 24 (82.8 \%) of the 29 patients (Table 3). One patient with a poor treatment outcome died due to rapidly progressive HPS at week 5. Patients who achieved remission within 4 weeks did not receive additional treatment intensification by any other immunosuppressive drugs, biologicals or a second round of GC pulse therapy.

Table 2

Clinical signs and symptoms at the time of treatment intensification during 0-4 weeks and during 4-52 weeks

\begin{tabular}{|lll|}
\hline Clinical signs and symptoms & $\begin{array}{l}\text { During } \mathbf{0 - 4} \text { weeks } \\
\mathbf{n = 2 9}\end{array}$ & $\begin{array}{l}\text { During 4-52 weeks } \\
\mathbf{n = 1 8}\end{array}$ \\
\hline Fever $\left(>39.0^{\circ} \mathrm{C}\right), \%$ & 55.2 & 52.9 \\
\hline Rashes, \% & 37.9 & 35.2 \\
\hline Lymphadenopathy, \% & 10.3 & 11.8 \\
\hline Hepatosplenomegaly, \% & 6.9 & 11.8 \\
\hline Elevated liver enzymes, \% & 58.6 & 29.4 \\
\hline Pericarditis, \% & 10.3 & 0 \\
\hline Pleuritis, \% & 17.2 & 0 \\
\hline Interstitial pneumonia, \% & 6.9 & 0 \\
\hline Arthritis, \% & 37.9 & 33.3 \\
\hline Hemophagocytic syndrome, \% & 13.8 & 0 \\
\hline DIC, \% & 13.8 & 0 \\
\hline $\begin{array}{l}\text { CRP elevation without clinical signs and symptoms, } \\
\%\end{array}$ & 0 & 11.1 \\
\hline DIC, disseminated intravascular coagulation & & \\
\hline
\end{tabular}


Table 3

Treatment regimen in the patients with and without the event of poor treatment outcome.

\begin{tabular}{|c|c|c|c|}
\hline Treatment & $\begin{array}{l}\text { With the } \\
\text { event }^{a} \\
(n=29)\end{array}$ & $\begin{array}{l}\text { Without the } \\
\text { event } \\
(n=42)\end{array}$ & $p$-value \\
\hline $\begin{array}{l}\text { Initial PSL dose (mg/kg/day) } \\
\text { at week } 0 \text {, mean } \pm \text { SD }\end{array}$ & $0.97 \pm 0.15$ & $0.72 \pm 0.23$ & $<0.001$ \\
\hline GC pulse at week $0, \mathrm{n}(\%)$ & $23(79.3)$ & $11(26.2)$ & $<0.001$ \\
\hline $\begin{array}{l}\text { Additional GC pulse } \\
\text { within } 4 \text { weeks, } \mathrm{n}(\%)\end{array}$ & $17(58.6)$ & 0 & - \\
\hline $\begin{array}{l}\text { Additional immunosuppressive } \\
\text { drugs at the event of poor treatment outcome, } n(\%)\end{array}$ & $24(82.8)$ & 0 & - \\
\hline MTX, n (\%) & $10(34.5)$ & - & - \\
\hline CyA, n (\%) & $4(13.8)$ & - & - \\
\hline Tac, n (\%) & $4(13.8)$ & - & - \\
\hline TCZ, n (\%) & $2(6.9)$ & - & - \\
\hline MTX + TCZ, n (\%) & $1(3.4)$ & - & - \\
\hline CyA + TCZ & $3(10.3)$ & - & - \\
\hline \multicolumn{4}{|c|}{$\begin{array}{l}\text { aPatients who received two and more pulse glucocorticoid (GC) therapy or any immunosuppressive } \\
\text { drugs within } 4 \text { weeks due to disease progression or relapse were defined as having the event of the } \\
\text { poor treatment outcome at week } 4 \text {. }\end{array}$} \\
\hline
\end{tabular}

\section{Relapse after achieving clinical remission at week 4.}

Overall, 42 patients achieved remission by 4 weeks on oral GC either with or without a single GC pulse. Relapse after achieving clinical remission was observed in 18 of these patients during a 4 - 52-week follow-up (Figure 1). The median time to relapse was 21 weeks (interquartile range 16 - 27). Clinical signs and symptoms at the time of relapse are shown in Table 2. Interestingly, unlike patients with a poor treatment outcome during 0-4 weeks, no severe organ damage was observed at the time of relapse between 4 and 52 weeks.

\section{Clinical characteristics of patients with a poor treatment outcome at week 4.}


Patients with poor treatment outcomes had more serositis and HPS at baseline, and a significantly higher mSFS. WBC count, serum ferritin, AST and LDH levels at baseline were higher in patients with a poor treatment outcome, and the modified Pouchot score and severity index was also higher (Table 1). The initial prednisolone dose was higher and initial GC pulse treatment was more frequent for patients with a poor treatment outcome than in the remaining patients (Table 3 ).

\section{Factors associated with poor treatment outcome.}

We selected WBC count, PIt count, AST, LDH, and ferritin as factors potentially associated with poor treatment outcome at week 4 because these parameters are useful for the early diagnosis of MAS (16) or HPS (17). The mSFS was included in the model as a measure of the severity of organ damage due to AOSD. Univariable logistic regression analysis revealed that WBC, ferritin and mSFS were indeed significantly associated with poor treatment outcome at week 4 . We then conducted multivariable logistic regression analyses, selecting age, WBC count, Plt count, ferritin, LDH, and mSFS as covariates of interest (Table 4). Notably, only WBC count remained significantly associated with poor outcome (odds ratio per 1000/ $\mu$ increment: 1.12, 95\% confidential interval [Cl] 1.04-1.29), while Plt count, ferritin, LDH, and mSFS were no longer statistically significant (Table 4). 
Table 4

Associated factors with the poor treatment outcome at week 4

\begin{tabular}{|c|c|c|c|c|}
\hline & \multicolumn{2}{|c|}{ Univariable analysis } & \multicolumn{2}{|c|}{ Multivariable analysis ${ }^{b}$} \\
\hline & OR $(95 \% \mathrm{Cl})$ & $p$ & OR $(95 \% \mathrm{Cl})$ & $p$ \\
\hline Age, per one year increment & $1.02(0.99-1.04)$ & 0.259 & $1.00(0.97-1.04)$ & 0.995 \\
\hline WBC, per $1000 / \mu$ increment & $1.14(1.05-1.24)$ & 0.003 & $1.16(1.04-1.29)$ & 0.010 \\
\hline Plt, per $1 \times 10^{4} / \mu \mathrm{l}$ increment & $0.97(0.94-1.01)$ & 0.180 & $0.98(0.92-1.04)$ & 0.457 \\
\hline Ferritin, per $1000 \mathrm{ng} / \mathrm{ml}$ increment & $1.05(1.01-1.10)$ & 0.014 & $1.02(0.98-1.06)$ & 0.450 \\
\hline LDH, per $100 \mathrm{U} / \mathrm{l}$ increment & $1.05(0.98-1.12)$ & 0.147 & $1.19(0.95-1.49)$ & 0.125 \\
\hline AST & $1.00(1.00-1.00)$ & 0.829 & & \\
\hline mSFS & $2.25(1.18-4.29)$ & 0.014 & $1.64(0.79-3.42)$ & 0.186 \\
\hline Modified Pouchot score & $2.00(1.37-2.90)$ & $<0.001$ & & \\
\hline Hemophagocytic syndrome & $4.14(0.97-17.6)$ & 0.055 & & \\
\hline Severity Index & $1.89(1.27-2.81)$ & 0.002 & & \\
\hline \multicolumn{5}{|c|}{$\begin{array}{l}\text { Age, WBC, Plt, ferritin, LDH, and mSFS were selected as covariates of interest. Modified Pouchot score } \\
\text { and severity index were not included in the multivariable model because these contained WBC and } \\
\text { ferritin. }\end{array}$} \\
\hline \multicolumn{5}{|c|}{$\begin{array}{l}\text { WBC, white blood cell count; PIt, platelet count; LDH, lactate dehydrogenase; AST, aspartate } \\
\text { transferase; mSFS, modified systemic feature score; Severity index; severity index of Japanese } \\
\text { Ministry of Health, Labour and Welfare. }\end{array}$} \\
\hline
\end{tabular}

\section{The WBC count at baseline predicts poor treatment outcome at week 4.}

We performed a ROC curve analysis in order to investigate the power of the WBC count for predicting the likelihood of a poor treatment outcome at week 4 (Figure 2A). The area under the ROC curve was 0.737 ( $95 \% \mathrm{Cl}: 0.618-0.856, p=0.001$ ) and analysis of the AUC showed that the best cut-off for the WBC count was $13,050 / \mu \mathrm{l}$ for predicting a poor treatment response, with a sensitivity of $72 \%$ and specificity of $65 \%$. The cumulative proportion of patients with a poor treatment outcome over 4 weeks was $60.0 \%$ in those with a WBC $\geq 13,050 / \mu \mathrm{l}$ but only $23.5 \%$ with a WBC $<13,050 / \mu \mathrm{l}$. The mean time to the event was significantly shorter by log-rank testing for patients with a WBC $\geq 13,050 / \mu$ l relative to those with a WBC $<13,050 / \mu \mathrm{l}(21.3 \pm 1.5$ vs. $27.9 \pm 0.9$ days) (Figure $2 \mathrm{~B})$.

\section{Safety.}

Adverse events over the 52-week follow-up in all 71 patients were evaluated. In the 29 patients with a poor treatment outcome, serious bacterial infections occurred in $3(10.3 \%)$, cytomegalovirus infection in 7 (24.1\%), deep fungal infection in $1(3.4 \%)$, and bone fracture in one. Two of the $29(6.9 \%)$ patients died 
due to severe bacterial infections at week 6 and 18. In 42 patients without such a poor treatment outcome, serious bacterial infection occurred in only 1 (2.4\%), cytomegalovirus infection in $2(4.8 \%)$, and deep fungal infection in one (2.4\%). Bacterial pneumonia, pneumocystis pneumonia, herpes zoster, tuberculosis, and non-tuberculous mycobacterial infections were not reported.

\section{Discussion}

The present study found that about $40 \%$ of newly-diagnosed patients with AOSD had a poor response to initial GC therapy within the first 4 weeks. We assessed mSFS and HPS as indicators of the severity of organ damage and confirmed that patients with a poor treatment outcome had higher mSFS and more HPS than those responding to treatment, as previously reported (18). However, our multivariable analysis revealed that increased WBC count was independently associated with poor response to initial GC therapy, while the mSFS and HPS, as well as other candidate factors (thrombocytopenia, elevated liver enzymes, high serum ferritin) were not. Thus, the novel observation here is that increased baseline WBC count is an independent important prognostic factor predicting the response to initial GC therapy of newly-diagnosed patients with AOSD.

AOSD is heterogeneous, with patients manifesting different proportions of systemic features and organ damage depending on the type of systemic or chronic articular pattern (19). Nonetheless, in the present study, epidemiological findings and the proportions of patients with pleuritis, pericarditis, HPS, and DIC at AOSD onset were similar to those in previous cohort studies in Japan and other countries, and the relapse rate was almost the same as in these previous studies (20-26). In our cohort, $23.9 \%$ of the 71 patients had arthritis at the onset, but no high-fever $\left(\geq 39.0^{\circ} \mathrm{C}\right)$, serositis, ILD, HPS, or DIC. Interestingly, the present study (Table 2) and previous studies showed that patients suffered less serious complications at relapse than at initial onset (20).

The classification criteria were proposed for MAS of febrile systematic JIA (27), with $45 \%$ and $56 \%$ of AOSD patients meeting these criteria according to two published studies $(28,29)$. Unfortunately, we were unable to examine the rate of MAS complications according to these sJIA classification criteria because data on fibrinogen and triglycerides were not available in many cases. In the present study, $14 \%$ of patients did have HPS diagnosed by bone marrow aspiration, but we could not establish who had clinically-diagnosed MAS in the absence of HPS.

In patients with AOSD, neutrophils infiltrate into skin, lymph nodes, and liver $(2,30)$, resulting in macrophage activation, and induction of pro-inflammatory cytokines (31-34). Importantly, the present study suggests that increased WBC counts predict a poor prognosis of AOSD early on, before complications of HPS or DIC may set in. More intensive combination therapies with high-dose GC and other immunosuppressive drugs might therefore be an appropriate induction treatment strategy for patients with WBC $\geq 13,050 / \mu \mathrm{l}$ at baseline, before progression to MAS. Additionally, previous studies had suggested that serum IL-18 levels are useful for predicting MAS in S-JIA $(16,35,36)$. Further studies with 
a prospective and multicentered design in Rare Disease Data Registry of Japan would provide valuable data on the role of IL-18 as well as high WBC counts also in AOSD (trial number: UMIN000043071).

Different prognostic factors have been reported for AOSD, depending on study design and the treatment outcomes selected as the end-point (18, 20-24, 37-49). A previous nationwide epidemiological survey of AOSD in Japan in 2010 showed that patients receiving GC pulse therapy were those who had had more serositis, HPS, higher neutrophil counts, and higher serum ferritin levels than those who did not receive GC pulse therapy (23). Previous studies showed that HPS, lymphadenopathy, the presence of lung disease, and liver involvement were associated with a poor prognosis. A higher systemic score and elevated serum ferritin were also reported as negative factors $(40,41,44,45,47)$. The univariable analysis of the present study also confirmed that these factors were associated with poor treatment outcome, and notably our multivariable analysis confirmed the clinical significance of increased WBC count as an independent prognostic factor.

When interpreting the results of our study, the inherent limitations of a monocentric observational retrospective study must be considered. First, our cohort may have included more patients with a severe course of systemic AOSD, because it consisted only of patients referred from other institutes who required specialized treatment at our university medical center. Second, the attending physician might have initiated intensive treatment for patients with severe organ damage or HPS at baseline, regardless of treatment responsiveness. However, we confirmed that additional treatment intensification was not conducted for the purpose of reduction of GC dose. Combination therapy of GCs and immunosuppressive drugs was not administered early in the remission induction therapy. Third, we were unable to analyze factors associated with poor treatment outcome at 1 year, because 14 patients were transferred to other hospitals after achieving remission.

\section{Conclusions}

The present study showed that about $40 \%$ of newly-diagnosed AOSD patients had a poor response to the initial standard oral GC therapy with or without GC pulse therapy and that the severity of AOSD (modified Pouchot score and severity index), HPS, and mSFS were associated with this poor treatment outcome. Multivariable analysis clearly demonstrated that a higher WBC count at baseline independently predicted poor treatment responsiveness, and that the most valuable cutoff was a WBC count of $\geq 13,050 / \mu \mathrm{l}$. Our findings provide important information for determining the initial treatment strategy of newly-diagnosed AOSD. Prospective cohort studies need to be conducted to validate this result.

\section{Abbreviations}

\section{ALT}

alanine aminotransferase

AOSD

adult-onset Still's disease 


\section{AST}

aspartate aminotransferase

$\mathrm{Cl}$

confidential interval

CRP

C-reactive protein

CyA

cyclosporine

DIC

disseminated intravascular coagulation

ESR

erythrocyte sedimentation rate

GC

glucocorticoid

$\mathrm{Hb}$

hemoglobin

HPS

hemophagocytic syndrome

LDH

lactate dehydrogenase

MAS

macrophage activation syndrome

mSFS

modified systemic feature score

MTX

methotrexate

Plt

platelet

PSL

prednisolone

SJIA

systemic juvenile idiopathic arthritis

ROC

Receiver-operating characteristic

Severity Index

the severity index of the Japanese Ministry of Health

Labour and Welfare

S.D.

standard deviation

Tac 
tacrolimus

TCZ

tocilizumab

WBC

white blood cell.

\section{Declarations}

\section{Ethics approval and consent to participate}

This study was conducted in accordance with the Declaration of Helsinki and the Ethical Guidelines for Epidemiological Research in Japan. The study was approved by the Ethics Committee of Tokyo Medical and Dental University (M2019-301).

\section{Consent for publication}

Not applicable

\section{Availability of data and materials}

All of the data supporting the conclusions of this article are included within the article.

\section{Competing interests}

Tokyo Medical and Dental University received unrestricted research grants for the salary of the members in Department of Lifetime Clinical Immunology from Abbvie Japan, Asahi-Kasei, Ayumi Pharmaceutical Corporation, Chugai Pharmaceutical Co., Ltd., CSL Behring K.K., Japan Blood Products Organization, Nippon Kayaku and UCB Japan Co. Ltd. TS has received research grants from AsahiKASEI Co., Ltd., Daiichi Sankyo., and Ono Pharmaceutical. TS has received honoraria from Abbvie Japan Co., Ltd., AsahiKASEl Co., Ltd., Astellas Pharma Inc., Ayumi Pharmaceutical, Bristol Myers Squibb K.K., Chugai Pharmaceutical Co., Ltd., Eli Lilly Japan K.K., Mitsubishi-Tanabe Pharma Co., Ono Pharmaceutical, Pfizer Japan Inc., Takeda Pharmaceutical Co. Ltd., and UCB Japan Co. Ltd. NK has received research grants from Chugai Pharmaceutical Co., Ltd., UCB Japan Co. Ltd, CSL Behring K.K., Ayumi Pharmaceutical, Japan Blood Products Organization, and Novartis Pharma K.K.. NK has received honoraria from Eisai Co., Ltd., AbbVie GK, Asahi KASEl Pharma Co., Novartis Pharma K.K., Japan Blood Products Organization, Kissei Pharmaceutical Co.LTD., Ono Pharmaceutical, Mitsubishi-Tanabe Pharma Co.. NK has received medical writing fees from AbbVie GK, Asahi Kasei Pharma Co, Chugai Pharmaceutical Co., LTD. SY received grants and personal fees from Abbvie, Asahi Kasei, Chugai Pharmaceutical, Ono pharmaceuticals, Eisai, Tanabe-Mitsubishi Pharmaceutical, personal fees from Eli Lilly, GlaxoSmithKline, and Pfizer. All other authors have declared no conflicts of interest.

\section{Funding}


This work was supported by grants from the Ministry of Health, Labour and Welfare, Japan (20FC1050).

\section{Authors' contributions}

F Kondo, T Sugihara, and S Yasuda were responsible for conception and design, data collection and analysis, critical revision, and manuscript writing. $\mathrm{NU}, \mathrm{HH}, \mathrm{TH}, \mathrm{NK}$, and $\mathrm{MM}$ were responsible for conception and design, data collection and analysis, and critical revision. All authors read and approved the final manuscript.

\section{Acknowledgments}

The authors would like to acknowledge Fumitaka Mizoguchi in Tokyo Medical and Dental University.

\section{Availability of data and materials}

All of the data supporting the conclusions of this article are included within the article.

\section{References}

1. Bywaters EGL. Still's disease in the adult. Ann Rheum Dis. 1971;30:121-33.

2. Feist $E$, Mitrovic S, Fautrel B. Mechanisms, biomarkers and targets for adult-onset Still's disease. Nat Rev Rheumatol. 2018;14(10):603-18.

3. Efthimiou P, Georgy S. Pathogenesis and management of adult-onset Still's disease. Semin Arthritis Rheum. 2006;36(3):144-52.

4. Mimura T, Kondo Y, Ohta A, Iwamoto M, Ota A, Okamoto N, et al. Evidence-based clinical practice guideline for adult Still's disease. Mod Rheumatol. 2018;28(5):736-57.

5. Kaneko Y, Kameda H, Ikeda K, Ishii T, Murakami K, Takamatsu H, et al. Tocilizumab in patients with adult-onset still's disease refractory to glucocorticoid treatment: a randomised, double-blind, placebocontrolled phase III trial. Ann Rheum Dis. 2018;77(12):1720-9.

6. Minoia F, Davì S, Horne A, Demirkaya E, Bovis F, Li C, et al. Clinical features, treatment, and outcome of macrophage activation syndrome complicating systemic juvenile idiopathic arthritis: a multinational, multicenter study of 362 patients. Arthritis Rheumatol. 2014;66(11):3160-9.

7. Cabane J, Michon A, Ziza JM, Bourgeois P, Blétry O, Godeau P, et al. Comparison of long term evolution of adult onset and juvenile onset Still's disease, both followed up for more than 10 years. Ann Rheum Dis. 1990;49(5):283-5.

8. Kobayashi M, Takahashi Y, Yamashita H, Kaneko H, Mimori A. Benefit and a possible risk of tocilizumab therapy for adult-onset Still's disease accompanied by macrophage-activation syndrome. Mod Rheumatol. 2011;21(1):92-6.

9. Carter SJ, Tattersall RS, Ramanan AV. Macrophage activation syndrome in adults: recent advances in pathophysiology, diagnosis and treatment. Rheumatology. 2019;58(1):5-17. 
10. Ma Y, Meng J, Jia J, Wang M, Teng J, Zhu D, et al. Current and emerging biological therapy in adultonset Still's disease. Rheumatology. 2021;60(9):3986-4000.

11. Yamaguchi $M$, Ohta $A$, Tsunematsu $T$, Kasukawa R, Mizushima $Y$, Kashiwagi $H$, et al. Preliminary criteria for classification of adult Still's disease. J Rheumatol. 1992;19(3):424-30.

12. Asakura $H$, Takahashi $H$, Uchiyama T, Eguchi $Y$, Okamoto $K$, Kawasugi $K$, et al. Proposal for new diagnostic criteria for DIC from the Japanese Society on Thrombosis and Hemostasis. Thromb J. 2016;14:42.

13. Vojinovic J, Damjanov N, D'Urzo C, Furlan A, Susic G, Pasic S, et al. Safety and efficacy of an oral histone deacetylase inhibitor in systemic-onset juvenile idiopathic arthritis. Arthritis Rheum. 2011;63(5):1452-8.

14. Rau M, Schiller M, Krienke S, Heyder P, Lorenz H, Blank N. Clinical manifestations but not cytokine profiles differentiate adult-onset Still's disease and sepsis. J Rheumatol. 2010;37(11):2369-76.

15. Maruyama A, Kokuzawa A, Yamauchi Y, Kirino Y, Nagai H, Inoue Y, et al. Clinical features of elderlyonset Adult-onset Still's disease. Mod Rheumatol. 2021;34:862-8.

16. Shimizu M. Macrophage activation syndrome in systemic juvenile idiopathic arthritis. Immunol Med. 2021. doi:10.1080/25785826.2021.1912893. Online ahead of print.

17. Ramos-Casals M, Brito-Zerón P, López-Guillermo A, Khamashta MA, Bosch X. Adult haemophagocytic syndrome. Lancet. 2014;383(9927):1503-16.

18. Ruscitti P, lacono D, Ciccia F, Emmi G, Cipriani P, Grembiale RD, et al. Macrophage Activation Syndrome in Patients Affected by Adult-onset Still Disease: Analysis of Survival Rates and Predictive Factors in the Gruppo Italiano di Ricerca in Reumatologia Clinica e Sperimentale Cohort. J Rheumatol. 2018;45(6):864-72.

19. Vercruysse F, Barnetche T, Lazaro E, Shipley E, Lifermann F, Balageas A, et al. Adult-onset Still's disease biological treatment strategy may depend on the phenotypic dichotomy. Arthritis Res Ther. 2019;21(1):53.

20. Pouchot J, Sampalis JS, Beaudet F, Carette S, Décary F, Salusinsky-Sternbach M, et al. Adult Still's disease: manifestations, disease course, and outcome in 62 patients. Med (Baltim). 1991;70(2):11836.

21. Zeng T, Zou YQ, Wu MF, Yang CD. Clinical features and prognosis of adult-onset still's disease: 61 cases from China. J Rheumatol. 2009;36(5):1026-31.

22. Kong XD, Xu D, Zhang W, Zhao Y, Zeng X, Zhang F. Clinical features and prognosis in adult-onset Still's disease: a study of 104 cases. Clin Rheumatol. 2010;29(9):1015-9.

23. Asanuma YF, Mimura T, Tsuboi H, Noma H, Miyoshi F, Yamamoto $K$, et al. Nationwide epidemiological survey of 169 patients with adult Still's disease in Japan. Mod Rheumatol. 2015;25(3):393-400.

24. Kalyoncu U, Solmaz D, Emmungil H, Yazici A, Kasifoglu T, Kimyon G, et al. Response rate of initial conventional treatments, disease course, and related factors of patients with adult-onset Still's disease: Data from a large multicenter cohort. J Autoimmun. 2016;69:59-63. 
25. Sfriso P, Priori R, Valesini G, Rossi S, Montecucco CM, D'Ascanio A, et al. Adult-onset Still's disease: an Italian multicentre retrospective observational study of manifestations and treatments in 245 patients. Clin Rheumatol. 2016;35(7):1683-9.

26. Hu QY, Zeng T, Sun CY, Luo CN, Liu S, Ding TT, et al. Clinical features and current treatments of adultonset Still's disease: a multicentre survey of 517 patients in China. Clin Exp Rheumatol. 2019;37(Suppl 121(6):52-7.

27. Ravelli A, Minoia F, Davì S, Horne A, Bovis F, Pistorio A, et al. 2016 Classification Criteria for Macrophage Activation Syndrome Complicating Systemic Juvenile Idiopathic Arthritis: A European League Against Rheumatism/American College of Rheumatology/Paediatric Rheumatology International Trials Organisation Collaborative Initiative. Arthritis Rheumatol. 2016;68(3):566-76.

28. Ahn SS, Yoo BW, Jung SM, Lee SW, Park YB, Song JJ. Application of the 2016 EULAR/ACR/PRINTO Classification Criteria for Macrophage Activation Syndrome in Patients with Adult-onset Still Disease. J Rheumatol. 2017;44(7):996-1003.

29. Tada Y, Inokuchi S, Maruyama A, Suematsu R, Sakai M, Sadanaga Y, et al. Are the 2016 EULAR/ACR/PRINTO classification criteria for macrophage activation syndrome applicable to patients with adult-onset Still's disease? Rheumatol Int. 2019;39(1):97-104.

30. Kim HA, Kwon JE, Yim H, Suh CH, Jung JY, Han JH. The pathologic findings of skin, lymph node, liver, and bone marrow in patients with adult-onset still disease: a comprehensive analysis of 40 cases. Med (Baltim). 2015;94(17):e787.

31. Choi JH, Suh CH, Lee YM, Suh YJ, Lee SK, Kim SS, et al. Serum cytokine profiles in patients with adult onset Still's disease. J Rheumatol. 2003;30(11):2422-7.

32. Kim HA, An JM, Nam JY, Jeon JY, Suh CH. Serum S100A8/A9, but not follistatin-like protein 1 and interleukin 18, may be a useful biomarker of disease activity in adult-onset Still's disease. J Rheumatol. 2012;39(7):1399-406.

33. Komiya A, Matsui T, Nogi S, Iwata K, Futami H, Takaoka H, et al. Neutrophil CD64 is upregulated in patients with active adult-onset Still's disease. Scand J Rheumatol. 2012;41(2):156-8.

34. Jamilloux Y, Gerfaud-Valentin M, Martinon F, Belot A, Henry T, Sève P. Pathogenesis of adult-onset Still's disease: new insights from the juvenile counterpart. Immunol Res. 2015;61(1-2):53-62.

35. Shimizu M, Yokoyama T, Yamada K, Kaneda H, Wada H, Wada T, et al. Distinct cytokine profiles of systemic-onset juvenile idiopathic arthritis-associated macrophage activation syndrome with particular emphasis on the role of interleukin-18 in its pathogenesis. Rheumatology. 2010;49(9):1645-53.

36. Mizuta M, Shimizu M, Inoue N, Ikawa Y, Nakagishi Y, Yasuoka R, et al. Clinical significance of interleukin-18 for the diagnosis and prediction of disease course in systemic juvenile idiopathic arthritis. Rheumatology. 2021;60(5):2421-6.

37. Kim HA, Sung JM, Suh $\mathrm{CH}$. Therapeutic responses and prognosis in adult-onset Still's disease. Rheumatol Int. 2012;32(5):1291-8. 
38. Kim YJ, Koo BS, Kim YG, Lee CK, Yoo B. Clinical features and prognosis in 82 patients with adultonset Still's disease. Clin Exp Rheumatol. 2014;32(1):28-33.

39. Bae CB, Jung JY, Kim HA, Suh CH. Reactive hemophagocytic syndrome in adult-onset Still disease: clinical features, predictive factors, and prognosis in 21 patients. Med (Baltim). 2015;94(4):e451.

40. Ruscitti P, Cipriani P, Masedu F, lacono D, Ciccia F, Liakouli V, et al. Adult-onset Still's disease: evaluation of prognostic tools and validation of the systemic score by analysis of 100 cases from three centers. BMC Med. 2016;14(1):194.

41. Ruscitti P, Rago C, Breda L, Cipriani P, Liakouli V, Berardicurti O, et al. Macrophage activation syndrome in Still's disease: analysis of clinical characteristics and survival in paediatric and adult patients. Clin Rheumatol. 2017;36(12):2839-45.

42. Seo JY, Suh CH, Jung JY, Kim AR, Yang JW, Kim HA. The neutrophil-to-lymphocyte ratio could be a good diagnostic marker and predictor of relapse in patients with adult-onset Still's disease: A STROBE-compliant retrospective observational analysis. Med (Baltim). 2017;96(29):e7546.

43. Yang JW, Lee E, Seo JY, Jung JY, Suh CH, Kim HA. Application of the international league against rheumatism classification criteria for systemic juvenile idiopathic arthritis as a prognostic factor in patients with adults-onset Still's disease. Pediatr Rheumatol Online J. 2018;16(1):9.

44. Yang XP, Wang M, Li TF, Li W, Zhang L, Liu SY. Predictive factors and prognosis of macrophage activation syndrome associated with adult-onset Still's disease. Clin Exp Rheumatol. 2019;37(Suppl 121(6):83-8.

45. Di Benedetto P, Cipriani P, lacono D, Pantano I, Caso F, Emmi G, et al. Ferritin and C-reactive protein are predictive biomarkers of mortality and macrophage activation syndrome in adult onset Still's disease. Analysis of the multicentre Gruppo Italiano di Ricerca in Reumatologia Clinica e Sperimentale (GIRRCS) cohort. PLoS One. 2020;15(7):e0235326.

46. Kang JH. Risk factors associated with relapse of adult-onset Still disease in Korean patients. Med (Baltim). 2020;99(50):e23579.

47. Ruscitti P, Berardicurti O, lacono D, Pantano I, Liakouli V, Caso F, et al. Parenchymal lung disease in adult onset Still's disease: an emergent marker of disease severity-characterisation and predictive factors from Gruppo Italiano di Ricerca in Reumatologia Clinica e Sperimentale (GIRRCS) cohort of patients. Arthritis Res Ther. 2020;22(1):151.

48. Wang R, Li T, Ye S, Tan W, Zhao C, Li Y, et al. Macrophage activation syndrome associated with adultonset Still's disease: a multicenter retrospective analysis. Clin Rheumatol. 2020;39(8):2379-86.

49. Yin R, Wang G, Yang X, Zhang L, Wang S, Li T, et al. Identification of prognostic factors and construction of a nomogram for patients with relapse/refractory adult-onset Still's disease. Clin Rheumatol. 2021. doi:10.1007/s10067-021-05722-7. Online ahead of print..

\section{Figures}




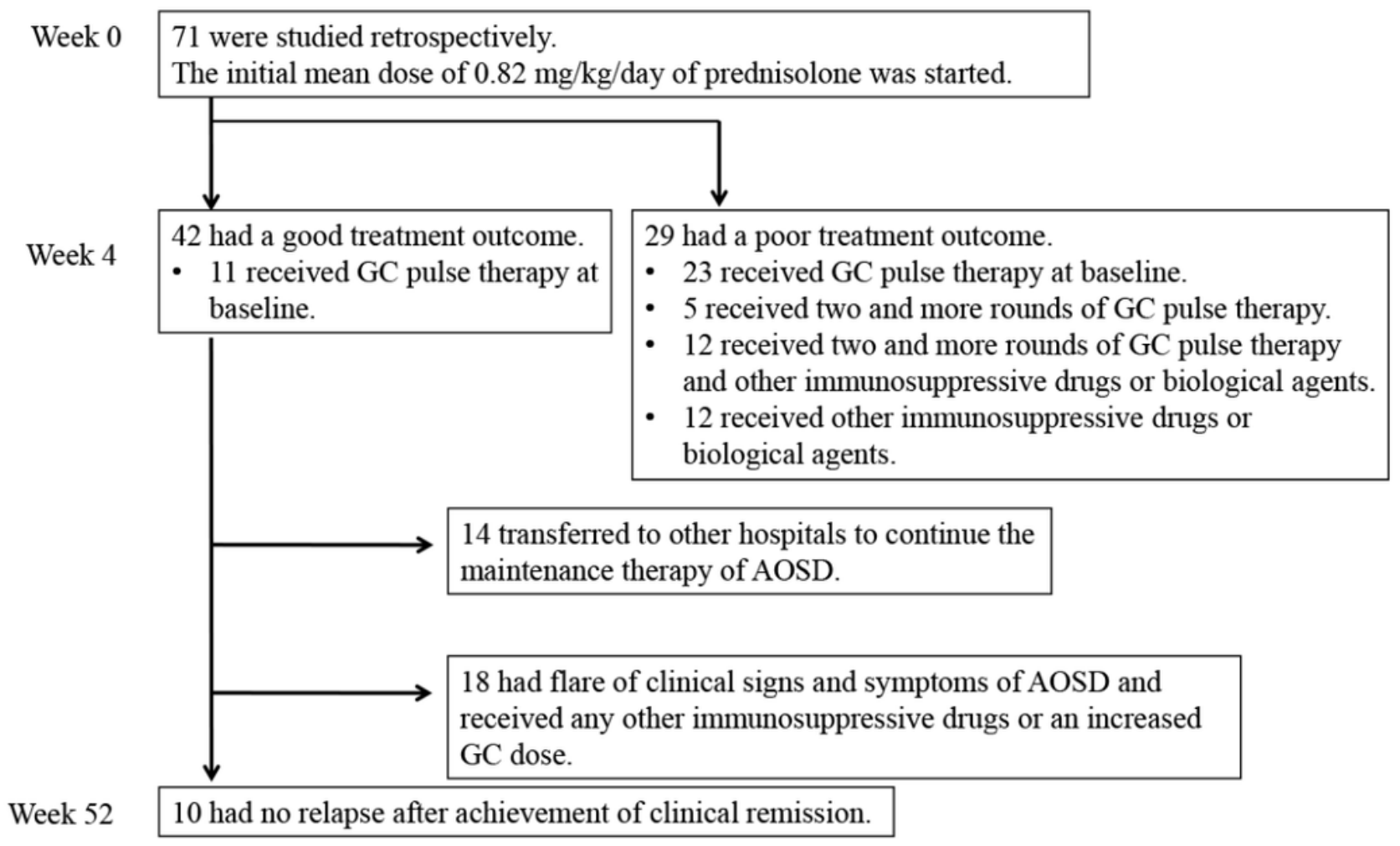

\section{Figure 1}

Patient screening and follow-up, and treatment outcomes The initial mean \pm S.D. dose of $0.82 \pm 0.23$ $\mathrm{mg} / \mathrm{kg} /$ day of prednisolone was started in 71 newly-diagnosed patients, with 34 also receiving glucocorticoid (GC) pulse therapy at baseline. A poor treatment outcome was defined as a poor treatment response within 4 weeks. The latter was defined as administration of two or more rounds of GC pulse therapy or the addition of any other immunosuppressive drugs within 4 weeks, due to failure to achieve remission or due to relapse. According to this definition, 29 patients had a poor treatment outcome at week 4 . The remaining 42 had a good treatment outcome at week 4, but 18 of them had relapsed by week 52. 
A

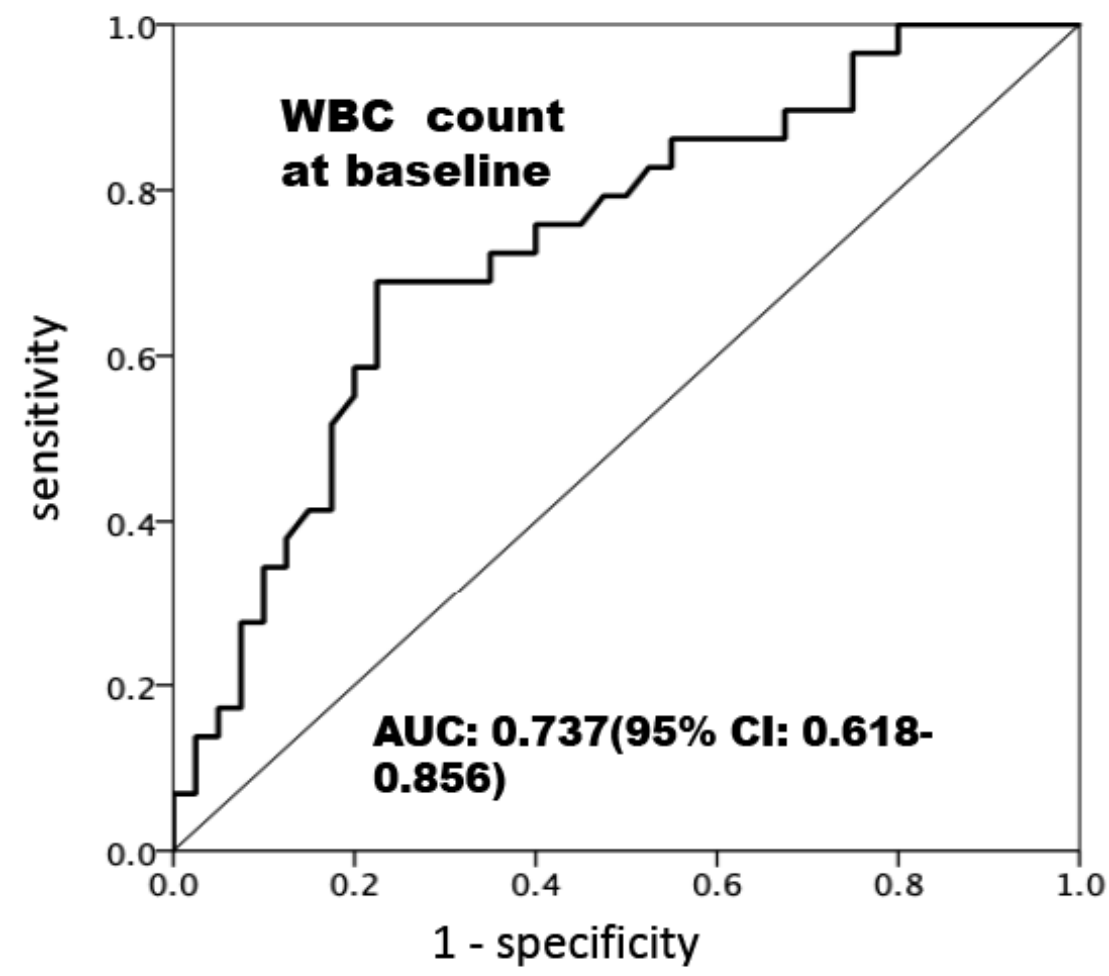

B

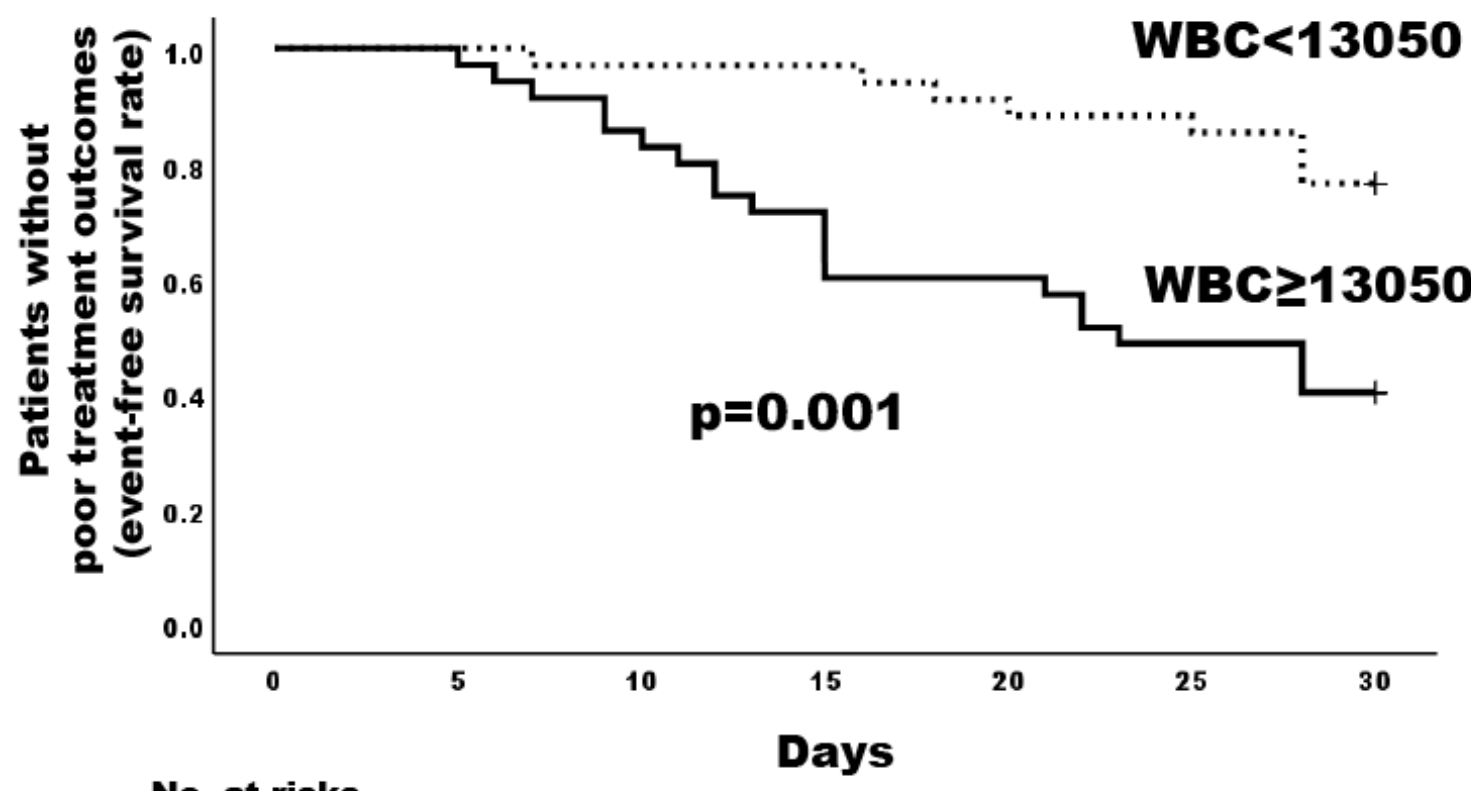

No. at risks

WBC $<1303034$

WBC $\geq 1305035$

24

21

17

13

\section{Figure 2}

Association of WBC count with a poor treatment outcome during 4 weeks Receiver-operating characteristic (ROC) curve for WBC (A). The area under the ROC curve was 0.737 (95\% Cl: 0.618-0.856, $p=0.001$ ); the analysis showed that the best cut-off for WBC was $13,050 / \mu \mathrm{l}$, providing a sensitivity of $72 \%$ and a specificity of $65 \%$. Analysis using the Kaplan-Meier method and the log-rank test (B). Cumulative 
rate of patients with a poor treatment outcome was $60.0 \%$ in those with $\mathrm{WBC} \geq 13,050 / \mu \mathrm{l}$ and $23.5 \%$ in those with $\mathrm{WBC}<13,050 / \mu \mathrm{l}$. 